\title{
Precise Ideal Value of the Universal Gravitational Constant G
}

\author{
Abed Elkarim S. Abou Layla \\ Independent Researcher, Gaza City, Palestine \\ Email: a.k.aboulayla@gmail.com
}

How to cite this paper: Abou Layla, A.E.S. (2017) Precise Ideal Value of the Universal Gravitational Constant G. Journal of High Energy Physics, Gravitation and Cosmology, 3, 248-253.

https://doi.org/10.4236/jhepgc.2017.32020

Received: January 2, 2017

Accepted: March 14, 2017

Published: March 17, 2017

Copyright $\odot 2017$ by author and Scientific Research Publishing Inc. This work is licensed under the Creative Commons Attribution International License (CC BY 4.0).

http://creativecommons.org/licenses/by/4.0/

c) (i) Open Access

\begin{abstract}
In this paper, we are going to rely on the first law in physics through which we can obtain a precise ideal value of the universal gravitational constant, a thing which has not happened so far. The significance of this law lies in the fact that, besides determining a precise ideal value of the gravitational constant, it connects three different physical disciplines together, which are mechanics, electromagnetism and thermodynamics. It is what distinguishes this from other law. Through this law, we have created the theoretical value of the gravitational constant $G_{i}$ and we found it equivalent to $6.674010551359 \times 10^{-11}$ $\mathrm{m}^{3} \cdot \mathrm{kg}^{-1} \cdot \mathrm{s}^{-2}$. In the discussion, the table of measurements of the gravitational constant was divided into three groups, and the average value of the first group $G_{1}$ which is the best precision, equals the following sum $6.67401 \times 10^{-11}$ $\mathrm{m}^{3} \cdot \mathrm{kg}^{-1} \cdot \mathrm{s}^{-2}$, and it's the same equal value to the ideal value $G_{i}$ that results from the law, as shown through our research that any other experimental values must not exceed the relative standard uncertainty which has a certain amount that is equivalent to a value of $5.325 \times 10^{-5}$ and that's a square value of the fine-structure constant.
\end{abstract}

\section{Keywords}

Gravitational Constant, Newtonian Parameter of Gravitation, Khromatic Theory, CODATA

\section{Introduction}

Although 3 centuries have elapsed since Newton set forth his gravitational law, physiology has been unable so far to create an exact theoretical value for the universal gravitational constant with no available values of the gravitational constant values except those values concluded by scientific experiments, especially conducted for obtaining the most accurate values of this constant.

We are going, in this research, to surmount this problem by way of setting 
forth a universal gravitational constant sole theory value, to be calculated through an index of a law known in the Khromatic theory as "The Law of Gravitational Constant" [1], although another problem yet lies here, which is that all results of experiments relating to determining the value of gravitational constants are confined to two values: a greater value and a lower value.

To overcome this problem, we put forth a supposition that a certain marginal velocity can be a basis for calculating a gravitational greater value acceptable as an ideal value within a certain error rate. And to ascertain the validity of the hypothesis we compared, through discussion, the values we obtained with those on the gravitation Table 2 of 2014 CODATA, as the comparison showed that in both cases the values were significantly close together, a thing that enabled us to solve the discrepancy between the theoretical and experimental values, consequently modifying Table 2, thereby we will have left behind an era of incessant attempts to find out the most accurate value of the gravitational constant.

\section{Finding the Accurate and Approximate Value of the Gravitation Constant}

\subsection{The Precise Ideal Value of $G$}

The law of gravitational constant looks like this:

$$
G_{i}=\propto\left(\frac{k_{B}}{e} c\right)^{2} \mathrm{~m}^{3} \mathrm{~kg}^{-1} \mathrm{~s}^{-2}
$$

as,

$G_{i}:$ ideal Universal gravitational constant $\left(\mathrm{m}^{3} \cdot \mathrm{kg}^{-1} \cdot \mathrm{s}^{-2}\right)$

$C:$ Speed of light in vacuum $(\mathrm{m} / \mathrm{s})$

$e$ : Elementary charge (colum)

$k_{B}:$ Boltzmann constant $\left(J / k^{\circ}\right)$

$\propto$ : Complex constant "multiplying more than one constant"

$=10^{-19}\left(\mathrm{mC}^{2} \cdot \mathrm{k}^{2} \cdot \mathrm{J}^{-2} \cdot \mathrm{kg}^{-1}\right)$

We are not going in our discussion, to deal with the method of the inference of this law, because of that it will be through another search that will be published completely, but we will content ourselves by reviewing the law and finds the precise ideal value of gravity through it.

Taking the values of the constants above from an abbreviated list of the 2014 CODATA recommended values of the fundamental constants of physics and chemistry, we get

$$
\begin{aligned}
& C: 299792458(\mathrm{~m} / \mathrm{s}) \\
& e: 1.6021766208(98) \times 10^{-19}(\text { colum }) \\
& k_{B}: 1.38064852(79) \times 10^{-23}\left(\mathrm{~J} / \mathrm{k}^{\circ}\right)
\end{aligned}
$$

So, using substitution in the value of constants we get the precise value of the gravitation constant equaling: 


$$
\begin{gathered}
G_{i}=10^{-19}\left(\frac{1.38064852 \times 10^{-23}}{1.6021766208 \times 10^{-19}} \times 299792458\right)^{2} \mathrm{~m}^{3} \cdot \mathrm{kg}^{-1} \cdot \mathrm{s}^{-2} \\
G_{i}=6.674010551359 \times 10^{-11} \mathrm{~m}^{3} \cdot \mathrm{kg}^{-1} \cdot \mathrm{s}^{-2}
\end{gathered}
$$

\subsection{The Expected Value of the Gravitation Constant}

Perhaps the ideal precise value of the gravitation constant is suitable for the static large blocks or those having negligible velocity-induced increment.

As for small masses moving at high speeds, it is more suitable to deal with relativity when calculated, however, we can handle expected values of the gravitational constant for experiments in which the body's velocity is so limited that the block's increment may be overlooked.

And to find such values, we can suppose that the block's laboratory speed limit should not exceed the orbital speed of electron in an atom of hydrogen and consequently the maximum expected gravitational value should not exceed a maximum value of the gravitational constant that is calculable using the equation.

$$
G_{\max }=\frac{G_{i}}{\left(1-\alpha^{2}\right)} \mathrm{m}^{3} \cdot \mathrm{kg}^{-1} \cdot \mathrm{s}^{-2} \text { as, }
$$

$\alpha$ : fine - structure constant $=7.2973525664 \times 10^{-3}$

And on calculation of this value we get the following:

$$
G_{\max }=6.674365970388 \times 10^{-11} \mathrm{~m}^{3} \cdot \mathrm{kg}^{-1} \cdot \mathrm{s}^{-2}
$$

Hence we can deduce the ideal standard uncertainty vale $\Delta G$ from the equation:

$$
\Delta G_{i}=G_{\max }-G_{i}=0.000355400102671 \times 10^{-11} \mathrm{~m}^{3} \cdot \mathrm{kg}^{-1} \cdot \mathrm{s}^{-2}
$$

And the ideal value of the relative standard uncertainty is $\bar{u}_{r}$ of the equation:

$$
\bar{u}_{r}=\frac{\Delta G_{i}}{G_{i}}=5.325135448 \times 10^{-5}
$$

which is a somewhat an acceptable value.

\section{Relationship between $\alpha$ and $\bar{u}_{r}$}

Since

$$
\begin{aligned}
\Delta G_{i} & =G_{\max }-G_{i} \mathrm{~m}^{3} \cdot \mathrm{kg}^{-1} \cdot \mathrm{s}^{-2} \\
G_{\max } & =\frac{G_{i}}{\left(1-\alpha^{2}\right)} \mathrm{m}^{3} \cdot \mathrm{kg}^{-1} \cdot \mathrm{s}^{-2},
\end{aligned}
$$

Thus

$$
\Delta G_{i}=\frac{G_{i}}{\left(1-\alpha^{2}\right)}-G_{i}=\alpha^{2} G_{i} \mathrm{~m}^{3} \cdot \mathrm{kg}^{-1} \cdot \mathrm{s}^{-2},
$$

and

$$
\bar{u}_{r}=\frac{\Delta G_{i}}{G_{i}}=\frac{\alpha^{2} G_{i}}{G_{i}}=\alpha^{2}
$$




\section{Discussion}

In this discussion we are going to compare the ideal values we had got by theoretical means and the documented experimental values in CODATA gravitational tables, and we will show that the values are close in both cases.

\subsection{Comparison of the Ideal and Results of Measurements of Gravitational Constant}

Table 1, borrowed from CODATA Recommended Values of the Fundamental Physical Constants, 2010, summarizes the results of measurements of the Newtonian parameter of gravitation relevant to the 2010 adjustment [2].

In this table there are three groups of measurements [3].

- The first such group consists of six measurements with the average value of

$$
G_{1}=6.67401 \times 10^{-11} \mathrm{~m}^{3} \cdot \mathrm{kg}^{-1} \cdot \mathrm{s}^{-2}
$$

Standard uncertainty $0.00019 \times 10^{-11}$ and relative standard uncertainty 28.5 ppm;

- The second one consists of four measurements with the average value of

$$
G_{2}=6.67250 \times 10^{-11} \mathrm{~m}^{3} \cdot \mathrm{kg}^{-1} \cdot \mathrm{s}^{-2}
$$

Standard uncertainty $0.00016 \times 10^{-11}$ and relative standard uncertainty 24 ppm;

- The third one consists of one measurement with the value of

$$
G_{3}=6.67559 \times 10^{-11} \mathrm{~m}^{3} \cdot \mathrm{kg}^{-1} \cdot \mathrm{s}^{-2}
$$

Standard uncertainty $0.00027 \times 10^{-11}$ and relative standard uncertainty 40 ppm.

Therefore, we conclude that the ideal value of the gravitational constant

\begin{tabular}{|c|c|c|c|c|}
\hline Source & Identification $^{a}$ & Method & $10^{-11} \mathrm{~m}^{3} \cdot \mathrm{kg}^{-1} \cdot \mathrm{s}^{-2}$ & $\begin{array}{l}\text { Rel.stand. } \\
\text { uncert. ur }\end{array}$ \\
\hline Luther and Towler (1982) & NIST-82 & Fiber torsion balance, dynamic mode & $6.67248(43)$ & $6.4 \times 10^{-5}$ \\
\hline Karagioz and Izmailov (1996) & TR\&D-96 & Fiber torsion balance, dynamic mode & $6.6729(5)$ & $7.5 \times 10^{-5}$ \\
\hline Bagley and Luther (1997) & LANL-97 & Fiber torsion balance, dynamic mode & $6.67398(70)$ & $1.0 \times 10^{-4}$ \\
\hline Quinn et al. (2001) & BIPM-01 & $\begin{array}{l}\text { Strip torsion balance, Compensation mode, static } \\
\text { deflection }\end{array}$ & $6.67559(27)$ & $4.0 \times 10^{-5}$ \\
\hline Kleinevoß (2002) and Kleinvoß et al. (2002) & UWup-02 & Suspended body, displacement & $6.67422(98)$ & $1.5 \times 10^{-4}$ \\
\hline Armstrong and Fitzgerald (2003) & MSL-03 & Strip torsion balance, compensation mode & $6.67387(27)$ & $4.0 \times 10^{-5}$ \\
\hline Schlamminger et al. (2006) & UZur-06 & Stationary body, weight change & $6.67425(12)$ & $1.9 \times 10^{-5}$ \\
\hline Luo et al. (2009) and Tu et al. (2010) & HUST-09 & Fiber torsion balance, dynamic mode & $6.67349(18)$ & $2.7 \times 10^{-5}$ \\
\hline Parks and Faller (2010) & JILA-10 & Suspended body, displacement & $6.67234(14)$ & $2.1 \times 10^{-5}$ \\
\hline
\end{tabular}
equals the sum

Table 1. Summary of the results of measurements of the Newtonian constant of gravitation relevant to the 2010 adjustment. 


$$
G_{i}=6.674010551359 \times 10^{-11} \mathrm{~m}^{3} \cdot \mathrm{kg}^{-1} \cdot \mathrm{s}^{-2}
$$

which is extremely close to the average value $G_{1}$, that equals the following sum

$$
G_{1}=6.67401 \times 10^{-11} \mathrm{~m}^{3} \cdot \mathrm{kg}^{-1} \cdot \mathrm{s}^{-2}
$$

So we can choice the first group of $G$ measurements as the best precision group of all others.

\subsection{Comparison of the Ideal and 2014 CODATA-Recommended Value of the Gravitational Constant [4]}

We learn from Table 2 the recommended values of 2014 CODATA [4] as follows:

That is, based upon the above table, the experimental value of the gravitational constant should range from a maximum value of $G_{\max }$ equaling $6.674390 \times 10^{-11}$ to a maximum value $G_{\min }$ equaling $6.673770 \times 10^{-11}$ with $G_{0}$ as the arithmetic mean of the two values that equals $6.67408 \times 10^{-11}$.

\subsubsection{The Ideal Value of the Gravitational Constant Equals the Sum}

$$
G_{i}=6.674010551359 \times 10^{-11} \mathrm{~m}^{3} \cdot \mathrm{kg}^{-1} \cdot \mathrm{s}^{-2}
$$

which is extremely close to the gravitational experimental value, that equals the following sum

$$
G=6.67408 \times 10^{-11} \mathrm{~m}^{3} \cdot \mathrm{kg}^{-1} \cdot \mathrm{s}^{-2}
$$

\subsubsection{Comparison of the Extent and Rate of Error}

When comparing the ideal quantity of standard uncertainty, which equals

$$
\Delta G_{i}=0.000355400102671 \times 10^{-11} \mathrm{~m}^{3} \cdot \mathrm{kg}^{-1} \cdot \mathrm{s}^{-2}
$$

To its counterpart mentioned in Table 2, which has the value:

$$
\Delta G=0.00031 \times 10^{-11} \mathrm{~m}^{3} \cdot \mathrm{kg}^{-1} \cdot \mathrm{s}^{-2}
$$

we find great similarity in values.

\subsubsection{Comparison of the Relative Error Rate}

Likewise, when comparing the ideal value of the relative standard uncertainty, which equals:

$$
\bar{u}_{r}=5.325135448 \times 10^{-5}
$$

To its counterpart contained in Table 2 which has the value:

$$
u_{r}=4.7 \times 10^{-5}
$$

Table 2. 2014 CODATA- recommended values of gravitation $\mathrm{G}, \Delta \mathrm{G}, \bar{u}_{r}$, Concise form.

\begin{tabular}{cc}
\hline \multicolumn{2}{c}{ Newtonian constant of gravitation $G$} \\
\hline Value & $6.67408 \times 10^{-11} \mathrm{~m}^{3} \cdot \mathrm{kg}^{-1} \cdot \mathrm{s}^{-2}$ \\
Standard uncertainty $\Delta G$ & $0.00031 \times 10^{-11} \mathrm{~m}^{3} \cdot \mathrm{kg}^{-1} \cdot \mathrm{s}^{-2}$ \\
Relative standard uncertainty $u_{r}$ & $4.7 \times 10^{-5}$ \\
Concise form & $6.67408(31) \times 10^{-11} \mathrm{~m}^{3} \cdot \mathrm{kg}^{-1} \cdot \mathrm{s}^{-2}$ \\
\hline
\end{tabular}


Table 3. Updated the values of gravitation $G, \Delta G, \bar{u}_{r}$, Concise form.

\begin{tabular}{cc}
\hline \multicolumn{2}{c}{ ideal Newtonian constant of gravitation $G_{\boldsymbol{i}}$} \\
\hline Value & $6.6740105 \times 10^{-11} \mathrm{~m}^{3} \cdot \mathrm{kg}^{-1} \cdot \mathrm{s}^{-2}$ \\
fine-structure constant $\alpha$ & $7.2973525664 \times 10^{-3}$ \\
Standard uncertainty $\Delta G$ & $0.0003554 \times 10^{-11} \mathrm{~m}^{3} \cdot \mathrm{kg}^{-1} \cdot \mathrm{s}^{-2}$ \\
Relative standard uncertainty & $\bar{u}_{r}$ \\
Concise form & $5.325 \times 10^{-5} \alpha^{2}$ \\
\hline
\end{tabular}

we also find great similarity in values.

Therefore, we conclude that all ideal values we have obtained through the theoretical equations are extremely close to their experimental counterparts which we had got from Table 2, which shows the recommended values of 2014 CODATA, except that the ideal values are more accurate, having been theoretically concluded, and as such, the data of Table 2 may be updated and substituted for the ideal values as illustrated below in Table 3 .

\section{Conclusions}

There is a precise ideal value of the universal gravitational constant which equals $6.674010551359 \times 10^{-11}$.

That may be calculated through a theoretically concluded equation of its own, and the cause of discrepancy of the gravitation value is attributable to the circumstances of the experiment as well as the sophistication of the nature and speed of particles used to measure the gravitational constant in such experiments.

\section{References}

[1] AbouLayla, A.K. (2016) The Khromatic Theoary. Al Manra, Palestinian Territories, p. 95.

[2] Mohr, P.J., Taylor, B.N. and Newell, D.B. (2012) CODATA Recommended Values of the Fundamental Physical Constants: 2010. https://arxiv.org/abs/1203.5425

[3] Netchitailo, V.S. (2016) 5D World-Universe Model. Gravitation. Journal of High Energy Physics, Gravitation and Cosmology, 2, 328-343. https://doi.org/10.4236/jhepgc.2016.23031

[4] The CODATA Value, Newtonian Constant of Gravitation. http://physics.nist.gov/cgi-bin/cuu/Value?bg 
Submit or recommend next manuscript to SCIRP and we will provide best service for you:

Accepting pre-submission inquiries through Email, Facebook, LinkedIn, Twitter, etc. A wide selection of journals (inclusive of 9 subjects, more than 200 journals)

Providing 24-hour high-quality service

User-friendly online submission system

Fair and swift peer-review system

Efficient typesetting and proofreading procedure

Display of the result of downloads and visits, as well as the number of cited articles Maximum dissemination of your research work

Submit your manuscript at: http://papersubmission.scirp.org/

Or contact jhepgc@scirp.org 